\title{
DIKSI LIRIK LAGU TARLINGDUT KARYA ABDUL ADJIB: KAJIAN STILISTIKA
}

\author{
Esi Yulistiana*, Sumarlam, Soediro Satoto \\ Pascasarjana Universitas Sebelas Maret Surakarta, Indonesia \\ *Corresponding author: esiysutanto@gmail.com
}

\begin{tabular}{ll}
\hline \hline INFORMASI ARTIKEL & \multicolumn{1}{c}{ ABSTRAK } \\
\hline Sejarah Artikel & Tujuan penelitian ini adalah untuk mengetahui penggunaan diksi \\
Diterima: $14 / 8 / 2018$ & serta fungsinya dalam lirik lagu Tarlingdut karya Abdul Adjib. \\
Direvisi: $15 / 6 / 2019$ & Penelitian ini menggunakan metode deskriptif kualitatif. Data \\
Disetujui: $16 / 6 / 2019$ & penelitian berupa frasa, kata, dan kalimat dalam lirik lagu \\
Tersedia Daring: $29 / 6 / 2019$ & $\begin{array}{l}\text { Tarlingdut karya Abdul Adjib. Teknik pengumpulan data yang } \\
\text { digunakan dalam penelitian ini menggunakan teknik inventarisasi, }\end{array}$ \\
Kata Kunci: & baca-simak, dan pencatatan. Analisis data dalam penelitian ini \\
Tarlingdut & menggunakan model Milles dan Hubberman. Hasil penelitian \\
Diksi & menunjukkan bahwa empat buah lagu ciptaan Abdul Adjib \\
Stilistika & menggunakan diksi atau pilihan kata yang estetis dalam hal \\
& pemilihan kata. Selain itu, dalam lirik lagu Tarlingdut banyak \\
& menggunakan diksi yang diambil dari serapan bahasa (1) Jawa khas \\
& Cirebon dan (2) bahasa asing yang terdiri dari bahasa Arab, Inggris \\
dan China, serta pemanfaatan sinonim.
\end{tabular}

\section{ABSTRACT}

\section{Keywords: \\ Tarlingdut \\ Diction \\ Stylistics}

The purpose of this study was to find out the use of diction and its function in the lyrics of the Tarlingdut song by Abdul Adjib. This study used descriptive qualitative method. Research data in the form of phrases, words, and sentences in the Tarlingdut song lyrics by Abdul Adjib. The data collection technique used in this study uses inventory, read-read, and recording techniques. Data analysis in this study used the Milles and Hubberman models. The results showed that four songs written by Abdul Adjib used diction or aesthetic choice of words in terms of word selection. Besides that, in Tarlingdut's song lyrics, many uses diction taken from the language absorption of (1) Javanese typical of Cirebon and (2) foreign languages consisting of Arabic, English and Chinese, as well as the use of synonyms.

Copyright@ 2019, Esi Yulistiana, Sumarlam, Soediro Satoto This is an open access article under the CC-BY-3.0 license
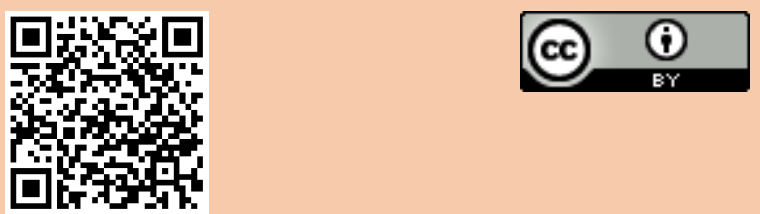

\section{PENDAHULUAN}

Language helps people communicate and think (Bahasa membantu manusia berkomunikasi dan berpikir)" (Thibodeau, Hendricks, \& Boroditsky, 2017). Pada hakikatnya bahasa kesusastraan memiliki perbedaan dengan bahasa sehari-hari. Hal ini membuktikan, bahwa bahasa sastra merupakan sarana penyampaian ekpresi serta ide gagasan dari pengarang 
tanpa ada batasan-batasan yang membelenggu. Bahasa dalam karya sastra memiliki kekhasan sendiri. Variasi penggunaan bahasa pada karya sastra disesuaikan kepentingan sastra untuk pembaca atau penikmat (Padmaningsih, 2014). Oleh sebab itu, ragam bahasa puitis dan unik mampu membangkitkan rasa penasaran, pemahaman isi serta memperlihatkan unsur estetik (indah) bagi penikmat karya sastra. Unsur estetik dalam dunia sastra tercermin dalam kesenian Tarling, yaitu kesenian tembang dan musik khas daerah Cirebon.

Tarling adalah salah satu jenis musik yang populer di wilayah pesisir pantai utara (Pantura) Jawa Barat, terutama wilayah Indramayu dan Cirebon. Nama Tarling diidentikkan dengan nama instrumen itar (gitar) dan suling (seruling) serta istilah "Yen wis mlatar gage eling (Jika banyak berdosa segeralah bertaubat)" (Rohmana, 2016). Tarling bagi masyarakat Cirebon merupakan kesenian tradisional yang mengakar kuat dari rakyat serta mampu mengikuti perkembangan zaman. Di samping memberikan nilai seni, tarling juga mampu memberikan pesan moral yang dalam bagi masyarakat pencintanya. Oleh karena itu, lirik lagu tarling perlu ditelusuri dengan menggunakan kajian stilistika.

Stilistika adalah kajian penggunaan bahasa dalam suatu penuturan, ragam, atau konteks tertentu. Stylistics, as an academic discipline, is "a method of linking linguistic form, via reader inference, to interpretation in a detailed way and thereby providing as much evidence as possible for and against particular interpretations of texts (stilistik, sebagai disiplin akademis, adalah "sebuah metode yang menghubungkan bentuk linguistik, melalui ketidaksadaran pembaca, dengan interpretasi secara terperinci dan dengan demikian memberikan bukti sebanyak mungkin untuk dan melawan interpretasi teks tertentu) (Mohammadzadeh, 2017). Lebih lanjut, stilistika merupakan ilmu yang mengkaji fungsi artistik (unik/indah/khas) dalam penggunaan bahasa. Dengan kata lain, stilistika merupakan cabang dari ilmu linguistik yang menelaah penggunaan bahasa serta efek yang mampu ditimbulkannya dalam sebuah karya sastra. Ketika sebuah karya sastra mampu menggetarkan hati, mengharukan dan berisi keindahan menurut persepsi pembaca atau penikmat karya sastra tersebut, maka karya sastra tersebut memiliki kekhasan dan estetis.

Kekhasan dan efek estetis (keindahan) yang ditimbulkan oleh sebuah karya sastra merupakan kemampuan yang ada dalam diri penulis atau pencipta karya sastra dalam mengali, menyajikan, dan mengekploitasi bahasa. Begitu juga dalam hal menciptaan sebuah lirik lagu, pengarang secara bebas mengekploitasi tanpa batas dalam berkreasi dan menyajikan ragam keindahan bahasa dalam karyanya, sehingga mendapatkan tempat istimewa di hati pembaca atau penikmat karya sastra tersebut (Hardiningtyas, 2017).

Penting untuk memahami apa yang ingin disampaikan oleh seorang pengarang dalam hasil karyanya, oleh sebab itu perlu untuk memahami serta mengetahui penggunaan pilihan kata (diksi) dalam lirik lagu tarlingdut karya Abdul Adjib. Sumber data makalah ini merupakan lirik lagu tarlingdut karya Abdul Adjib, karena Abdul Adjib memberikan kesan khas dan banyak memanfaatkan pilihan kata dalam setiap hasil karyanya. Kekhasan inilah yang memperlihatkan bagaimana kepiawaian seorang maestro tarling Abdul Adjib dalam menyusun jalinan kata-kata dalam lirik lagu tarling ciptaanya. Menurut Pradopo (2017) penyair memilih kata yang setepattepatnya untuk menyuarakan perasaan dan isi pikirannya dengan setepat-tepatnya, seperti yang dialami batinnya dan mengekspresikannya dengan ekspresi yang dapat menjelmakan jiwanya tersebut. Diksi digunakan oleh pengarang untuk menuangkan gagasannya kepada orang lain agar tidak terjadi salah tafsir dan merasakan apa yang pengarang rasakan. Fungsi diksi adalah sebagai sarana mengaktifkan kegiatan berbahasa (komunikasi) yang dilakukan seseorang untuk menyampaikan maksud dan gagasannya kepada orang lain (Munir, 2013). 
Sastra lisan Jawa-Cirebon cukup beragam, tetapi yang menarik adalah seni tarling. Dua hal yang menarik dalam tarling, pertama ia dipandang sebagai hasil budaya hibrid, kedua, jika dibandingkan dengan jenis sastra lisan Jawa-Cirebon lainnya, seni tarling dipandang paling representatif mewakili sastra Jawa-Cirebon sebagai sastra liminalitas (Supriatin, 2012). Tarling merupakan salah satu jenis musik tradisional yang sangat populer di wilayah pesisir pantai utara (Pantura) Jawa Barat, terutama di wilayah Indramayu, Cirebon, Brebes dan Tegal. Tarlingdut sangat berbeda dengan dangdut. Tarling dangdut adalah jenis lagu berirama tarling yang dikarang dengan patokan gamelan diracik dengan melodi gitar petik, suling klasik dan tepak gendang khas seniman Indramayu-Cirebon yang terdiri dari gendang besar dan dua hingga gendang kepiting kecil yang dimainkan secara bersama-sama (Sudibyo, 2011). Adapun dangdut dapat dikatakan bahwa dangdut merupakan sebuah istilah yang muncul di sekitar tahun 1970an. Dalam kaitannya dengan sebuah jenis musik, istilah dangdut diduga berasal dari bunyi sepasang gendang yang dimainkan dengan teknik glissando, sehingga terdengar bunyi "dang' dan "dut". Selanjutnya, istilah tersebut digunakan untuk penamaan corak musik Melayu yang belakangan berkembang dengan nama musik dangdut (Muttaqin, 2010). Tidak seperti musik pada umumnya, yang menjadi media hiburan semata, musik dangdut juga berfungsi sebagai media komunikasi sosial. Musik yang memang memiliki bahasa universal, berhasil mengantarkan musik dangdut sebagai media komunikasi massa, seperti dakwah, menyampaikan pesan dan protes (Luaylik \& Khusyairi, 2012).

Tarling diakui sebagai jenis kesenian rakyat yang mengakar kuat pada hati masyarakat Pantura. Oleh sebab itu, perkembangan tarling mengikuti perubahan zaman dan masih mampu untuk bersaing dengan kesenian lainnya. Karena tarling memiliki tempat tersendiri bagi masyarakat pencintanya hingga kini. Lirik dalam lagu tarlingdut selalu menceritakan berbagai kisah kehidupan masyarakat Pantura, terutama dalam kehidupan sehari-hari. Lebih lanjut, (Soekarba, 2013) mengatakan "lirik lagu tarling selalu menceritakan kisah kehidupan seharihari yang sarat pesan moral, menggambarkan kehidupan masyarakat di pesisir Pantura Jawa Barat. Tema utama dalam lirik-lirik lagu tarling adalah nasihat, pegat-balen (kawin cerai), wayuan (poligami), demenan (cinta) masalah rumah tangga, pemujaan pada laki-laki, penderitaan perempuan, ketidakberdayaan perempuan, dan kebiasaan laki-laki pada masyarakat Kabupaten Indramayu (mabuk, maen, madon, minuman keras, judi, main perempuan)”. Tarling merupakan seni budaya yang menggunakan musik dan lagu (Maryani, Nurcahyani, Padmawati, \& Nurlina, 2014). Serapan bahasa Jawa khas Cirebon, bahasa asing yaitu bahasa Arab, Inggris dan China, serta pemanfaatan sinonim dikelompokkan ke dalam bagian diksi. Karena sesuai dengan teori jenis diksi yang dikemukakan oleh (Keraf, 2010), yaitu: denotasi, konotasi, kata abstrak, kata konkrit, kata umum, kata khusus, kata ilmiah, kata populer, jargon, kata slang, kata asing, dan kata serapan.

Alasan dipilihnya lirik tarlingdut karya Abdul Adjib, yaitu karena lirik lagu tarling syarat akan gaya bahasa dan diksi yang unik dan khas, bahkan olah kata yang dihasilkan dalam lirik tarling memiliki makna tersendiri. Diksi atau pilihan kata yang terdapat dalam lirik tarlingdut sangat berpengaruh dalam makna dan penyampian pesan atau ide gagasan. Hakikatnya, diksi memberikan keefektifan bagi penulis untuk menyampikan pesan. Melalui bahasa akan diketahui pula pola pikiran, memperlihatkan jiwa serta kepribadian penulis karya sastra (Fathoni, 2012).

Penelitian terdahulu yang telah dilakukan oleh Soekarba (2013) lebih condong mengenai studi kasus dalam lirik lagu tarling, kemudian Supriatin (2012) lebih menyoroti mengenai analisis fungsi tarling dan nilai-nilai tarling dalam masyarakat Cirebon khususnya, 
dan penelitian mengenai efektifitas seni budaya tarling Cirebon sebagai media peningkatan pengetahuan bagi ibu hamil di Kabupaten Cirebon (Maryani et al., 2014). Berbeda dengan ketiga penelitian terdahulu yang lebih merujuk pada lingkup tarling dan keseniannya, sedangkan penelitian ini lebih mengenai diksi lirik lagu tarling, terutama buah karya Abdul Adjib. Berdasarkan uraian singkat di atas, maka Tujuan penelitian ini yaitu mendeskripsikan penggunaan diksi (pilihan kata) yang dihadirkan Abdul Adjib dalam lirik lagu tarlingdut ciptaannya.

\section{METODE}

Bentuk penelitian ini adalah deskriptif kualitatif yaitu prosedur penelitian yang menghasilkan data deskriptif berupa kata-kata atau tulisan. Penelitian ini bertujuan menggambarkan, mengungkap, menjelaskan serta mendeskripsikan fenomena bahasa dan budaya sesuai dengan fakta di masyarakat yang berupa sistem tanda bahasa, symbol bahasa, dan makna dengan mengunakan pengkaidahan, metode, teknik penelitian, dan cara kerja penelitian sosiolog budaya (Padmaningsih, 2014). Sumber data dalam penelitian ini dibatasi dengan menggunakan 5 lirik lagu ciptaan Abdul Adjib. Hal ini dikarenakan banyaknya liriklirik lagu ciptaan Abdul Adjib yang tidak bisa ditelaah satu persatu. Alasan lainnya yaitu lima lirik lagu ini memiliki diksi yang unik dan indah. Adapun keempat lirik lagu-lagu ciptaan Abdul Adjib yang berjudul: (1) Kembang Boled, (2) Kembang Jambe Tutup Ketel, (3) Ragda Tua, (4) Penyakit Jaman, (5) Krisis Akhlak.

Metode penelitian yang digunakan dalam penelitian ini adalah metode penelitian kepustakaan (Library Research). Metode kepustakaan ini digunakan untuk menyusun konsep mengenai diksi yang terdapat dalam lirik lagu tarling karya Abdul Adjib. Adapun langkahlangkah penelitian kepustakaan menurut Kuhlthau (2002) adalah sebagai berikut.

(1) Pemilihan topik, pemilihan topik yang ingin dipilih berdasarkan beberapa pertimbangan yakni ketertarikan peneliti dalam suatu topik, inormasi yang tersedia, waktu yang tersedia dan kemungkinan keberhasilan penelitian. Dalam penelitian kepustakaan ini peneliti telah memutuskan untuk memilih topik mengenai diksi dalam lirik lagu tarling karya Abdul Adjib,

(2) Eksplorasi informasi. Di tahap ini peneliti melakukan eksplorasi informasi mengenai penelitian kepustakaan, diksi lirik lagu karya Abdul Adjib, hal ini sangat berguna dalam membantu peneliti dalam memperoleh informasi lengkap penelitian yang akan dilakukan),

(3) Menentukan fokus penelitian. Peneliti perlu menentukan fokus penelitian untuk membatasi dan memperjelas bahasan-bahasan yang akan dikaji dalam penelitian yang akan dilakukan. Beberapa langkah yang bisa dilakukan dalam membantu menentukan fokus penelitian yakni: 1) mengumpulkan data mengenai fokus yang memungkinkan untuk dilakukan, 2) menyusun fokus penelitian. Pada penelitian kepustakaan ini, peneliti telah menentukan fokus penelitian yang menjadi rumusan masalah yang akan dikaji dalam penelitian ini, yaitu mengenai penggunaan diksi dalam lirik lagu tarling karya Abdul Adjib.

(4) Pengumpulan Sumber Data. Peneliti melakukan pengumpulan sumber data yang berupa buku-buku yang tersedi di perpustakaan, jurnal-jurnal ilmiah terkait serta situs-situs internet yang menyediakan $e$-book dan artikel pengetahuan mendalam yang terkait dengan topik penelitian sehingga terkumpul sumber data yang diperlukan.

(5) Persiapan Penyajian Data. Pada tahapan ini peneliti akan melakukan penganalisisan dari setiap sumber data yang telah berhasil dikumpulkan. Sumber data yang telah berhadil 
dikumpulkan kemudian dianalisis berdasarkan kesediaan data yang terkait dengan okus penelitian yaitu diksi lirik lagu tarling.

(6) Penyusunan Laporan. Menyusun laporan disesuaikan dengan sistematika penulisan yang telah ditentukan.

Data yang diperlukan berupa informasi yang relevan dengan fokus penelitian, yaitu diksi lirik lagu tarling karya Abdul Adjib. Data dalam penelitian ini adalah data deskriptif yang berupa frasa, kata, kalimat serta kata serapan dalam kumpulan lirik lagu tarlingdut karya Abdul Adjib. Sumber data dalam penelitian ini diperoleh dari literatur-literatur yang relevan dengan penelitian, yaitu artikel-artikel pada e-journal ilmiah yang dapat diunduh di internet.

Teknik penggumpulan data yang digunakan dalam penelitian kepustakaan ini adalah dengan menggunakan metode dokumentasi, yaitu mencari data mengenai hal-hal atau variabel berupa catatan, buku, makalah atau artikel, jurnal dan sebagainya (Suharsimi, 2010). Teknik analisis data yang digunakan dalam penelitian ini adalah metode analisis isi (content analysis). Analisis isi adalah penelitian yang bersifat pembahasan mendalam terhadap isi suatu informasi. Dalam proses analisis ini, dilakukannya serangkaian proses memilah-milih, membandingkan, dan menggabungkan berbagai pengertian-pengertian, sehingga ditemukan yang sesuai (relevan). Guna mencegah serta mengatasi kesalahan informasi yang didapat karena kesalahan manusiawi penulis pustaka, maka perlu dilakukan pengecekan dan pembacaan berulang antar pustaka. Dalam penelitian kualitatif, peneliti harus berusaha mendapatkan data yang valid untuk itu dalam pengumpulan data, peneliti perlu mengadakan validitas data agar data yang diperoleh tidak invalid (cacat). Untuk menetapkan keabsahan data diperlukan teknik pemeriksaan. Pelaksanaan teknik pemeriksaan data didasarkan atas sejumlah kriteria tertentu. Ada 4 (empat) kriteria yang dapat digunakan, yaitu: derajat kepercayaan (credibility), keteralihan (transferability), kebergantungan (dependability), dan kepastian (confirmability) (Bachri, 2010).

\section{HASIL DAN PEMBAHASAN}

Penggunaan kata serapan dari bahasa lain sangat berpengaruh pada efek stilistika tarlingdut. Hal ini dikarenakan pilihan kata yang dipilih oleh penulis lirik lagu mampu memberikan kesan indah, unik, khas dan memperkuat maksud dari lirik lagu. Seperti yang dikatakan oleh Padmaningsih (2014) bahwa variasi penggunaan bahasa pada karya sastra disesuaikan kepentingan sastra untuk pembaca atau penikmat.

Berdasarkan penelitian terhadap kumpulan lirik lagu-lagu tarlingdut karya Abdul Adjib dapat diketahui adanya penggunaan diksi serta fungsinya. Diksi dalam lirik lagu karya Abdul Adjib sangat beragam, yaitu terdapat pemanfaatan kosakata serapan bahasa asing terutama bahasa Arab, China dan Inggris, serta adanya pemanfaatan sinonim. Jenis diksi menurut Keraf (2010) adalah: denotasi, konotasi, kata abstrak, kata konkrit, kata umum, kata khusus, kata ilmiah, kata populer, jargon, kata slang, kata asing, dan kata serapan. Berikut diksi dalam empat lirik lagu-lagu tarlingdut karya Abdul Adjib:

\section{Pemanfaatan Kosakata Bahasa Jawa}

Salah satu lirik lagu tarlingdut karya Abdul Adjib yang memanfaatkan kosa kata bahasa Jawa adalah: (1) Kembang Boled, yaitu: boled (ketela), kasep (tampan), A'a (sebutan untuk pria), gulati (mencari-cari), marek (mendekat), (2) Kembang Jambe Tutup Ketel, yaitu: ganjene (genitnya), bari (setelah), kadiran (kesombongan), (3) Ragda Tua, yaitu: damplek (tumpah), 
ngiplek (goyangan berlebihan), gage (cepat-cepatlah), (4) Penyakit Jaman, yaitu: matek (membuat/menyebabkan), bengien (dahulu kala), sekien (sekarang ini), bonggan (salahnya sendiri), kesirian (iri), (5) Krisis Akhlak, yaitu: lantarane (apa penyebabnya), keder (binggung), jlerit (jeritan atau teriakan histeris), ngleprak (terbaring tak berdaya di pinggir jalan).

Fungsi pemanfaatan kosakata bahasa Jawa khususnya khas Cirebon pada lirik lagu tarlingdut tersebut adalah untuk mengintensifkan makna, menguatkan latar si tokoh, sapaan, menguatkan kisah, menjelaskan makna dengan detail.

\section{Pemanfaatan Kosakata Bahasa Arab}

Kata "Allah" berasal dari dua kata "al" dan "ilah". Al adalah kata sandang (band bahasa Inggris the), dan ilah berarti yang kuat, dewa. Menurut Arifin (2014) mengatakan bahwa perkataan "Allah" berasal dari perkataan al-allah, dihapuskan hamzah dan diganti dengan alif lam ta'rif. Alif dan lam yang dimasukkan pada perkataan ilah berfungsi menunjukkan bahwa perkataan yang dimasukan itu (perkataan ilah) merupakan sesuatu yang telah dikenal dalam benak. Kedua-dua huruf tambahan itu menjadikan kata yang diletak menjadi makrifat. Selanjutnya dengan alasan mempermudah, hamzah yang berada antara dua lam yang dibaca (i) pada kata Al-Ilah tidak dibaca lagi sehingga berbunyi "Allah".

\section{.... Bocah cilik pada apal-apal Shio angka setan kawin, Ana dimistik ana cara di plus min/} ... (lirik Penyakit jaman)

Kata setan berasal dari bahasa Arab yaitu "syaithan". Para ulama berpendapat tentang asal kata 'syaithan' dalam dua pendapat. Pertama; kata syaithan berasal dari kata "satona" yang berarti jauh, karena setan jauh dari kebenaran atau jauh dari rahmat Allah, kedua; kata "syaithan" berasal dari kata "satona - syaithon" yang berarti binasa dan terbakar (Hasanah, 2014).

.... Ning penyakit jaman/Timbul rupa-rupa bentuk penipuan/... (lirik Penyakit jaman)

Kata jaman adalah jangka waktu yang panjang atau pendek yang menandai sesuatu; masa atau masa atau jangka rentang waktu tertentu di masa lalu atau masa sekarang. Kata zaman berasal dari kata "zamana". Kata zaman dalam kaitannya dengan posisinya sebagai salah satu kategori nahwu memiliki peran sebagai petunjuk waktu kejadian suatu kejadian baik yang terjadi pada masa lampau, sekarang, ataupun yang akan datang (Setiyadi, 2011).

\section{.... Dadi korban jaman krisis akhlak, Aduh Gusti Allah Maha Suci/.... (lirik krisis akhlak)}

Penggunaan bahasa Arab tergambar jelas dalam kata "akhlak" dan "Allah". Kata "akhlak" berasal dari bahasa Arab "jama" dari bentuk mufradatnya "khuluqum" yang berarti budi pekerti, perangai, tingkah laku dan tabiat, sedangkan menurut istilah adalah pengetahuan yang menjelaskan tentang baik dan buruk (benar dan salah), mengatur pergaulan manusia, dan menentukan tujuan akhir dari usaha dan pekerjaannya (Habibah, 2015).

Dari data-data di atas mengenai pemanfaatan kosakata bahasa Arab dalam kumpulan lirik lagu tarlingdut karya Abdul Adjib yaitu kata “ampun, Allah, setan, jaman, dan akhlak. Fungsi pemanfaatan kosakata bahasa Arab adalah untuk memperkuat makna lirik lagu, sarana ajaran moral religius, dan memberikan kesan intelektual bagi penulis lirik lagu. 


\section{Pemanfaatan Kosakata Bahasa Inggris}

... Hai Rangda Rangda tuwa sugi batur Manca negara, Ning luar negeri wis biasa Eropa lan Amerika/... (lirik Kembang jambe tutup ketel).

Kata Eropa berasal dari bahasa Inggris yaitu "Europe", yang berarti kb. Eropa (h). "Ero.pa /êropa/ adalah benua yang terletak di sebelah barat Asia, sebelah utara Afrika, dan sebelah timur Samudra Atlantik".

.... Perduli umur wis manula, Main tlepon, Main henpon, Ning internet ngaton, Pentinge mung senggak guyon/.... (lirik Rangda tua).

Kata tlepon, henpon dan internet merupakan kata yang berasal dari bahasa Inggris, yaitu: "telephone", "handphone" dan internet. Telepon adalah pesawat telekomunikasi yang menggunakan listrik dan kawat, untuk bercakap-cakap antara dua orang yang berjauhan. Handphone adalah telepon genggam, telepon seluler (ponsel) atau Hp adalah merupakan perangkat telekomunikasi elektronik yang mempunyai kemampuan dasar yang sama dengan telepon konvensional saluran tetap. Namun, internet adalah kependekan dari interconnectionnetworking seluruh jaringan komunikasi yang menggunakan media elektronik, yang telah menggunakan standar sistem global Transmission Control Protocol/Internet Protocol Suite (TCP/IP) sebagai protokol pertukaran paket (packet switching communication protocol). "TCP/IP (Transmission Control Protocol/Internet Protocol) adalah sekelompok protokol yang mengatur komunikasi data komputer di Internet" (Sari, Sudarsono, \& Hayadi, 2013). Internet/ intêrnèt adalah komputer jaringan komunikasi elektronik yang mengubungkan jaringan komputer dan fasilitas komputer yang terorganisasi di seluruh dunia melalui telepon atau satelit.

.... Nyetel kaset njoget ngiplek/ ... (lirik Rangda tua).

Kata kaset berasal dari kata "Kasete", yaitu: wadah plastik dengan pita magnetik yang dapat berputar dari satu gelendong ke gelendong yang lain, biasanya untuk mendengarkan musik atau video. Kaset/kasèt adalah, (1) wadah plastik dengan pita magnetik yang dapat berputar dari satu gelendong ke gelendong yang lain, (2) wadah tertutup untuk menyimpan film atau bahan yang peka cahaya.

.... Bocah cilik pada apal-apal Shio angka setan kawin, Ana dimistik ana cara di plus min/ ... (lirik Penyakit jaman)

Kata "plus" adalah "lebih atau berlebih" dan kata "min" merupakan kependekan dari kata "minus" yaitu mat kurang; dikurangi. Pada data lirik lagu berjudul "penyakit jaman" di atas, menggambarkan tentang seorang anak yang sudah menghapal shio mengenai angka setan dengan ilmu mistik dan dengan cara di tambah atau dikurangi.

\section{.... Tentara dilawan di gura-gura, Polisi kadang-kadang dimusuhi/... (lirik Krisis akhlak)}

Kata polisi dalam lirik lagu berjudul "krisis akhlak", yaitu berasal dari kata "police (suatu pranata umum sipil biasanya militaris, yang bertugas dalam menjaga ketertiban, keamanan serta menegakan keadilan atau hukum dalam wilayah suatu negara berdaulat)". 
Menurut Azhari (2011) istilah polisi pertama kali berasal dari Yunani yakni 'politeia' dari tokoh Plato yang berlatar belakang pemikiran bahwa suatu negara yang ideal sekali sesuai dengan cita-citanya, suatu negara yang bebas dari pemimpin negara yang rakus dan jahat, tempat keadilan dijunjung tinggi. Keragaman istilah lain dapat dilihat di Inggris dengan 'police', Jerman 'polizei', dan Belanda dengan 'politie'.

\section{Pemanfaatan Bahasa China}

\section{.... Nanging jaman sekien, Rabi tuku Ciam-si ngomong bahasen/.... (lirik Penyakit jaman)}

Data di atas menunjukkan adanya penggunaan bahasa China, yaitu kata Ciam-si. Menurut Hardiningtyas (2017), Puisi Ciam-si merupakan puisi ramalan yang umumnya digunakan masyarakat Tionghoa dalam ritual di Klenteng. Kemudian, Ciam-si dijabarkan menjadi ciamsi, qian-shi (bilah syair) yang umum masih dapat dijumpai pada Klenteng tradisional di Indonesia sekarang" (Kustedja, Sudikno, \& Salura, 2012). Kata Ciam-si (qianshi atau qiuqian) merupakan suatu cara mencari jawaban atas permasalahan diri yang dihadapi atau merupakan ramalan kuno khas kebudayaan suku Tionghoa berdasarkan 100 kertas syair. Bagi masyarakat Tionghoa, Ciam-si dipercaya dapat menuntun ke arah sebuah keberuntungan dan kebahagiaan serta menghapuskan nasib sial atau jelek.

\section{.... Angklop-angklop cilik kang diwolak-walik, Sapa wong kang bodo, Bisa tuku pindo,}

Regane sampe cepek jigo/.... (lirik Penyakit jaman)

Data di atas ditemukan dalam lirik lagu berjudul "penyakit jaman" karya Abdul Adjib. Penggunaan bahasa China ditemukan dalam kata "cepek jigo" yang berarti, " 100 " dan " 25 ". Angka-angka atau jumlah nominal uang di atas merupakan angka perhitungan dari bahasa Hokkian (Tionghoa), akan tetapi beberapa kata biasanya telah diadopsi oleh masyarakat Betawi dan Jakarta pada umunya. Bahasa Mandarin dan Hokkian diketahui memiliki hubungan kekerabatan dalam rumpun yang sama (Gapur, Siregar, \& Pujiono, 2018). Lebih lanjut, menurut Azzuhri (2015) mengatakan bahwa "sama akrabnya dengan kata-kata yang berasal dari khasanah bahasa Cina, seperti kata-kata 25 = Jigo, 50 = Gocap, $100=$ Cepek, $125=$ Cepek Jigo, $150=$ Pek Go, 200 = Nopek, 225 = Nopek Jigo, $250=$ Nopek Go, $300=$ Sapek, $500=$ Gopek". Angka Hokien yang paling berkesan adalah "Jie Sam Soe" yang berarti "2, 3, dan 4". Pemanfaatan kosakata bahasa China pada lirik lagu tarlingdut karya Abdul Adjib, adalah untuk menguatkan kisah, memberikan kesan intelek, mengintensifkan makna lebih dalam, dan memberikan gambaran tentang sesuatu yang baru.

\section{SIMPULAN}

Hasil penelitian dalam kumpulan lirik lagu-lagu tarlingdut karya Abdul Adjib meliputi: (1) Penggunaan aspek-aspek diksi (pilihan kata) dalam lirik lagu tarlingdut buah karya Abdul adjib, yaitu pemanfaatan kosakata bahasa Jawa dialek Cirebon, yang berfungsi untuk mengkonkretkan makna, sapaan, serta menguatkan latar sang tokoh. Pada lagu yang berjudul Kembang Boled ada 5 buah, yaitu: boled (ketela), kasep (tampan), A'a (sebutan untuk pria), gulati (mencari-cari), marek (mendekat). Lagu kedua yang berjudul Kembang Jambe Tutup Ketel ada 3 buah, yaitu: ganjene (genitnya), bari (setelah), kadiran (kesombongan). Lagu ketiga yang berjudul Ragda Tua ada 3 buah, yaitu: damplek (tumpah), ngiplek (goyangan berlebihan), 
gage (cepat-cepatlah). Lagu keempat yang berjudul Penyakit Jaman ada 5 buah, yaitu: matek (membuat/menyebabkan), bengien (dahulu kala), sekien (sekarang ini), bonggan (salahnya sendiri), kesirian (iri). Krisis Akhlak 4 buah, yaitu: lantarane (apakah penyebabnya), keder (binggung), jlerit (jeritan atau teriakan histeris), ngleprak (terbaring tak berdaya di pinggir jalan), sehingga total keseluruhan ada 20 buah. (2) Kekhasan dan efek estetis (keindahan) yang ditimbulkan oleh sebuah karya sastra merupakan kemampuan yang ada dalam diri penulis atau pencipta karya sastra dalam menggali, menyajikan, dan mengekploitasi bahasa, (3) Diksi merupakan pemilihan kata-kata yang dengan sengaja dihadirkan oleh penulis atau pencipta karya sastra dalam hal mengungkapkan ide gagasan yang diketahui dan dirasakannya. Penggunaan diksi dalam lirik lagu tarlingdut untuk memperoleh suatu tujuan yang diinginkan, yaitu efek puitis serta estetis (indah). (4) Penganalisisan terhadap lirik lagu tarling sebagai refleksi sastra liminalitas menunjukkan bahwa masyarakat Cirebon sebagai masyarakat perbatasan memiliki nilai-nilai moral. Tarling adalah seni masyarakat dengan pertunjukan gitar dan seruling, merupakan seni khas Cirebon yang kental dengan unsur budaya, petuah dan ragam cermin kehidupan masyarakat Cirebon.

Berdasarkan pembahasan lirik lagu tarling dan kesimpulan tersebut, maka perlunya untuk meningkatkan ragam penelitian mengenai lirik lagu tarlingdut terutama dalam usaha melestarikan kebudayaan daerah Cirebon. Penulis berharap penelitian stilistika mampu menambah khazanah penelitian sastra serta penelitian ini dapat menjadi referensi bagi penelitian berikutnya terutama dalam penelitian tentang tarling. Perlu adanya penelitian lanjutan mengenai tarlingdut, terutama dianalisis dengan menggunakan semiotik, sosiolinguistik.

\section{DAFTAR PUSTAKA}

Arifin, Z. (2014). Kata "Allah" dalam Al-Quran dan Alkitab Kajian Terhadap Pelarangan Menggunakan Kata “Allah” bagi Selain Muslim. Jurnal THEOLOGIA, 25(2), 153-176.

Azhari. (2011). Negara Hukum Indonesia Analisis Yuridis Normatifterhadap Unsur-Unsurnya. Jakarta: UI Press.

Azzuhri, M. (2015). Bahasa, Kuasa, dan Etnistitas. Pekalongan: STAIN Pekalongan Press.

Bachri, B. S. (2010). Meyakinkan Validitas Data melalui Triangulasi pada Penelitian Kualitatif. Jurnal Teknologi Pendidikan, 10(1), 46-62.

Fathoni, H. (2012). Gaya Bahasa dalam Syair “Al-i'tiraf” Karya Abu Nuwas: Sebuah Analisis Stilistik. At-Ta'dib, 7(2), 205-224.

Gapur, A., Siregar, D. S. P., \& Pujiono, M. (2018). Language Kinship Between Mandarin, Hokkien Chinnese and Japanase (Lexicostatistic Review). Aksara, 30(2), 301-318.

Habibah, S. (2015). Akhlak dan Etika dalam Islam. Jurnal Pesona Dasar, 1(4), 73-87.

Hardiningtyas, P. R. (2017). Stilistika dan Unsur Kealaman dalam Ciam Si: Puisi-Puisi Ramlan Karya Tan Lioe Ie. JENTERA: Jurnal Kajian Sastra, 4(2), 86-94.

Hasanah, U. (2014). Mengungkap Rahasia Setan dalam Al-Quran. Jurnal Hermeneutik, 7(1), 101-121.

Keraf, G. (2010). Diksi dan Gaya Bahasa. Jakarta: PT Gramedia Pustaka Utama.

Kustedja, S., Sudikno, A., \& Salura, P. (2012). Kosmologi Media Interpretasi Makna Pada Arsitektur Tionghoa Tradisional. Jurnal Sosioteknologi, 11(27), 194-226.

Luaylik, F., \& Khusyairi, J. A. (2012). Perkembangan Musik Dangdut Indonesia 1960an1990an. Jurnal Verleden, 1(1), 26- 39. 
Maryani, H., Nurcahyani, L., Padmawati, R., \& Nurlina, N. (2014). Effectiveness of Tarling Cirebonan Cultural Arts as a Media to Improve Pregnant Women's Knowledge in Cirebon District of West Java. Buletin Penelitian Sistem Kesehatan, 18(4), 421-429.

Mohammadzadeh, B. (2017). A Text World Theory Approach to the Teaching of Short Stories in an EFL context: A Pedagogical Stylistic Study. Journal of Language and Linguistic Studies, 13(2), 285-295.

Munir, S. (2013). Diksi dan Majas dalam Kumpulan Puisi Nyanyian dalam Kelam Karya Sutikno WS: Kajian Stilistika. Jurnal Sastra Indonesia, 2(1), 1-10.

Muttaqin, M. (2010). Musik Dangdut dan Keberadaannya di Masyarakat: Tinjauan dari Segi Sejarah dan Perkembangannya (Dangdut and Its Existence in the Society: The Review of Its History and Development). Harmonia: Journal Of Arts Research And Education, $7(2), 1-9$.

Padmaningsih, D. (2014). Gaya Bahasa dalam Tembang Tradisional Jawa. Etnografi, 14(2), 419-486.

Pradopo, R. D. (2017). Beberapa Teori Sastra, Metode Kritik, dan Penerapannya. Jakarta: Pustaka Pelajar.

Rohmana, J. A. (2016). Sastra Islam Nusantara. AKADEMIKA: Jurnal Pemikiran Islam, 21(1), $1-18$.

Sari, H. L., Sudarsono, A., \& Hayadi, B. H. (2013). Pengembangan Jaringan Local Area Network Menggunakan Sistem Ooperasi Linux Redhat 9 (Studi Kasus Pada Laboratorium Komputer SMA Negeri 1 Ujan Mas Kepahiang). Jurnal Media Infotama, 9(1), 165-189.

Setiyadi, A. C. (2011). Konsep Zaman dalam Nahwu (Tinjauan Sintaksis Semantis). At-Ta'dib, 6(2), 223-238.

Soekarba, S. R. (2013). Tragedi Cinta dan Rumah Tangga dalam Lirik Lagu Tarling Indramayuan (Studi Kasus terhadap Lirik Lagu Tarling Indramayuan). Paper presented at the International Conference on Indonesian Studies, Yogyakarta.

Sudibyo, N. (2011). Bahasa Jawa Pantura Tak Terpeta, Lagu-lagunya Merambah Nusantara. Paper presented at the Kongres International Bahasa Jawa, Surabaya.

Suharsimi, A. (2010). Prosedur Penelitian Suatu Pendekatan Praktik. Jakarta: Rineka Cipta.

Supriatin, Y. M. (2012). Teks Tarling: Representasi Sastra Liminitas (Analisis Fungsi dan Nilai-Nilai). Jurnal Metasastra, 5(1), 92 - 101.

Thibodeau, P. H., Hendricks, R. K., \& Boroditsky, L. (2017). How Linguistic Metaphor Scaffolds Reasoning. Trends in Cognitive Sciences, 21(11), 852-863. 